\title{
Peranan Statistika dan Pengembangan Karakter dalam Menghadapi Tantangan Era Revolusi Industri 4.0 dan Big Data pada SMAN 1 Praya
}

\author{
Agus Kurnia*, Mustika Hadijati, Desy Komalasari, Nurul Fitriyani \\ Prodi Matematika, FMIPA UNRAM, Universitas Mataram, Mataram, Indonesia
}

\begin{abstract}
Article history
Received: 05 November 2019

Revised: 08 November 2019

Accepted: 28 November 2019

*Corresponding Author:

Agus Kurnia

Prodi Matematika, FMIPA

UNRAM, Universitas Mataram,

Mataram, Indonesia

Email:

aguskurnia@unram.ac.id
\end{abstract}

\begin{abstract}
The development of science and technology provides changes to every aspect of human life including social, economic, educational and industrial changes which are now entering stage 4.0. The Era of the Industrial Revolution 4.0 is identical to the Internet of Things which produces Big Data that cannot be processed with conventional devices and requires special analysis. These changes require human resource development in science, education and character in order to continue to compete with the global world, especially the younger generation who will fill the industrial forward. The problem arises because most of the educational outcomes lack a link and match or a good match between tertiary education which causes students to feel wrong about their majors or the incompatibility of their needs and abilities in the industrial world which makes it difficult for them to find a work. Therefore, coaching efforts are needed so that students can be aware and prepare themselves to improve their quality both by increasing hardskills and soft skills to meet these needs. This community service activity is carried out by SMAN 1 Praya as one of the best high schools and is a reference school in West Nusa Tenggara. The method used is the direct learning method that is evaluated using self-assessment techniques conducted by students using google form. Evaluation results show an increase in students' knowledge of statistics and character development needed in the face of the industrial revolution 4.0 and Big Data after they have participated in this dedication activity.
\end{abstract}

Keywords: education; hardskills; softskills; human development; internet of things

Abtrak: Perkembangan ilmu pengetahuan dan teknologi memberikan perubahan terhadap setiap aspek kehidupan manusia diantaranya sosial, ekonomi, pendidikan dan juga perubahan industri yang sekarang masuk ke tahap 4.0. Era Revolusi Industri 4.0 ini identik dengan Internet of Thing yang menghasilkan data-data yang sangat banyak (Big Data) yang tidak bisa diolah dengan perangkat konvensional dan memerlukan analisis khusus. Perubahan ini menuntut adanya pengembangan sumber daya manusia baik dalam hal sains, pendidikan dan karakter agar bisa terus bersaing dengan dunia global khususnya generasi muda yang akan mengisi dunia industri kedepan. Permasalahannya muncul karena sebagian besar hasil pendidikan kurang memiliki link and match atau kecocokan baik antara pendidikan tinggi yang menyebabkan mahasiswa merasa salah menentukan jurusan maupun tidak cocoknya kebutuhan dan kemampuan mereka di dunia industri yang menyebabkan mereka susah mendapatkan pekerjaan. Oleh karena itu diperlukan upaya pembinaan agar para siswa bisa sadar dan mempersiapkan dirinya untuk meningkatkan kualitas dirinya baik dengan meningkatkan keterampilan (hardskills) maupun karakter (softskills) untuk memenuhi kebutuhan ini. Kegiatan pengabdian ini dilakukan SMAN 1 Praya sebagai salah satu sekolah menengah atas terbaik dan menjadi sekolah rujukan di Nusa Tenggara Barat. Metode yang digunakan yaitu metode 
pembelajaran langsung yang dievaluasi dengan menggunakan teknik penilaian diri (self assesment) yang dilakukan oleh para siswa dengan menggunakan google form. Hasil evaluasi menunjukan adanya peningkatan pengetahuan siswa terhadap statistika dan pengembangan karakter yang dibutuhkan dalam menghadapi revolusi industri 4.0 dan Big Data setelah mereka mengikuti kegiatan pengabdian ini.

Kata Kunci: edukasi; hardskills; softskills; pengembangan diri; internet of things

\section{PENDAHULUAN}

Revolusi Industri merujuk pada Revolusi Industri tahap empat dimulai pada Revolusi Industri pertama di Inggris pada tahun 1784 seiring dengan munculnya mesin uap dan mekanisasi yang menggantikan pekerjaan manusia, kedua pada akhir abad 19 dimana mesin produksi yang ditenagai oleh listrik diproduksi masal, ketiga pada tahun 1970 pada saat teknologi komputer untuk otomatisasi manufaktur, dan keempat pada saat ini ditandai dengan adanya perkembangan pesat pada bidang teknologi sensor, interkoneksi dan analisis data (Prasetyo \& Trisyanti, 2018). Sedangkan Big Data adalah istilah dari "kumpulan data yang berukuran sangat besar dan kompleks, sehingga tidak memungkinkan untuk diproses menggunakan perangkat pengelola database konvensional ataupun aplikasi pemroses data lainnya" (Maryanto, 2017).

Berkembanganya Revolusi Industri 4.0 bukan hanya berdampak pada bidang teknologi saja, tetapi berdampak juga pada bidang pendidikan, ekonomi, sosial, budaya, dan lain sebagainya. Masalah yang terjadi pada saat ini tidak semuanya bisa diselesaikan dengan cara cara sebelumnya. Sehingga dibutuhkan sumber manusia yang unggul, sadar dan dewasa untuk menyikapi perubahan saat ini. Kemunculan Revolusi Industri 4.0 ini juga membawa lonjakan data dan informasi yang besar, sehingga dibutuhkan kebijaksanaan dan juga metode analisis yang tepat untuk memproses informasi tersebut. Era ini memunculkan tantangan tersendiri yang disebut dengan era disrupsi dimana persaingan kerja menjadi tidak linier, dan munculnya kecerdasan artificial bisa menggantikan tenaga kerja manusia dengan robot yang lebih efisien, efektif dan murah (Yahya, 2018). Tetapi selain melahirkan Era Disrupsi, erar ini juga memberikan dampak positif dalam berbagai sektor, seperti pada sektor bisnis, seorang pimpinan bisa memanfaatkan Big Data tersebut dalam untuk mengetahui respon masyarakat terhadap produk perusahaannya, membantu mengambil keputusan yang tepat dan akurat berdasarkan data yang ada, membantu meningkatkan citra perusahaan, merencanakan usaha dengan mengetahui prilaku pelanggan, dan mengetahui trend pasar dan keinginan konsumen (Maryanto, 2017).

Tantangan yang muncul dari munculnya Revolusi Industri 4.0 dan Big Data ini bisa dihadapi dengan menyiapkan pelaksanaan pendidikan yang terintegrasi antara sumber daya manusia dengan kebutuhan zaman di era ini, dan juga menyiapkan pendidikan yang terintegrasi sehingga sumber daya manusia memiliki sumber daya manusia yang disiapkan yang juga dibekali dengan nilai nilai kemanusian yang diajakarkan dalam ilmu sosial humaniora (Prasetyo \& Trisyanti, 2018) sehingga sumber daya manusia harus bisa dikembangkan mulai dari pengetahuan (knowledge), keterampilan (skills), dan sikap (attitude) yang diperkaya dengan pendidikan karakter diantaranya adalah Minat (enthusiasm), komitmen (commitment) dan kejujuran (honesty) (Majelis Pendidikan Dewan Pendidikan Tinggi Kementerian Riset, 2017).

Peranan statistika dan pentingnya pengembangan inilah yang menjadi dasar pentingnya pengbadian ini, karena para siswa khususnya siswa SMA harus memahami pentingnya memanfaatkan analisis statistika dan mengembangkan karakter mereka sebelum menyelesaikan pendidikannya di SMA, baik dalam rangka mempersiapkan diri untuk menghadapi dunia industri ataupun dalam memilih program studi di Universitas, sehingga mereka bisa mengetahui arah pengembangan dirinya sesuai dengan minat dan bakat mereka juga sesuai dengan kebutuhan industri di masa yang akan datang. 
Kegiatan pengabdian pengembangan karakter untuk menghadapi revolusi industri 4.0 untuk siswa menengah atas pernah dilakukan dengan objek siswa SMK Global Mulia Cikarang, pengabdian tersebut dilakukan agar para siswa SMK bisa memahami konsep revolusi Industri 4.0 dan juga mengidentifikasi hard skills dan soft skills yang dibutuhkan (Global et al., 2018), objek pengbadian tersebut sangat tepat karena yang paling diorientasikan untuk bidang industri adalah siswa SMK, tetapi menurut pandangan kami, siswa SMA juga tidak kalah pentingnya untuk diberikan pengetahuan ini baik dalam memilih jurusan yang tepat maupun untuk mempersiapkan diri dalam memasuki dunia industri, sehingga ditambahkan pula dengan pemberian materi peranan statistika dalam menghadapi hal tersebut. Kemudian ada pula pengabdian dengan statistika untuk menghadapi era big data ini tetapi dengan objek mahasiswa PAI di IAI Qomarudin Gresik (Rufaidah et al., 2016), pengabdian ini memberikan workshop analisis data dengan menggunakan software Minitab dan SPSS.

\section{METODE}

PKegiatan inti dari pengabdian ini menggunakan metode pembelajaran langsung, yaitu dengan menggunakan metode ceramah kepada para peserta didik dengan memberikan materi-materi peranan statistika dan juga pengembangan karakter, pemberian materi ini menggunakan power point yang disertai dengan ilustrasi dan video yang berkaitan untuk menguatkan materi yang disampaikan juga menarik perhatian siswa.

Sedangkan tahapan-tahapan pengbadian seluruhnya, tergambar dalam tahapan di bawah ini:

a. Pelaksanaan pre-test dengan google form menggunakan smartphone atau laptop yang ada.

b. Menyampaikan materi tentang peranan statistika dalam menghadapi Revolusi Industri 4.0 dan Big Data

c. Menyampaikan Materi Pengembangan karakter siswa dalam menghadapi tantangan Revolusi Industri 4.0 dan Big Data

d. Pelaksanaan post-test.

\section{HASIL DAN PEMBAHASAN}

Kegiatan pengabdian ini dilaksanakan selama satu hari di SMAN 1 Praya. Objek Pengabdian dalam kegiatan ini adalah siswa-siswi SMAN 1 Praya kelas 12, sebanyak 58 siswa yang didominasi oleh perempuan sebanyak 37 dan 21 orang laki-laki.

Untuk melihat keberhasilan pengabdian ini kami menggunakan google form sebagai alat untuk melakukan pre-test dan post-test. Pertanyaan yang diajukan seputar identitas, rencana setelah lulus, jurusan yang dipilih jika masuk ke perguruan tinggi, cita-cita, karakter, pembelajaran matematika, dan tentang statistika dalam kaitannya dengan big data. Pelaksanaan pre-test ini dilakukan dengan menggunakan smartphone yang ada secara bergilir karena ada kebijakan sekolah untuk tidak membawa handphone/smartphone ke sekolah agar mereka fokus pada pembelajaran di kelas, sehingga waktu pelaksanaan pre-test dan post-test yang direncanakan bisa lebih singkat menjadi lebih lama.

Kegiatan dilanjutkan dengan pemaparan materi peranan statistika menghadapi tantangan era revolusi industri 4.0 dan big data. Materi ini bertujuan untuk meningkatkan kesadaran para siswa dalam menghadapi tantangan yang dihadapi saat ini sehingga bisa memotivasi para siswa agar mereka mempersiapkan diri sebaik mungkin baik dalam peningkatkan softskill dan hardskill mereka, yang 
salah satunya adalah kemampuan dalam menggunakan statistika. Materi ini juga dikaitkan dengan hasil pre-test yang telah mereka lakukan sebelumnya, sehingga pemateri bisa menekankan materi yang belum mereka ketahui atau pahami.

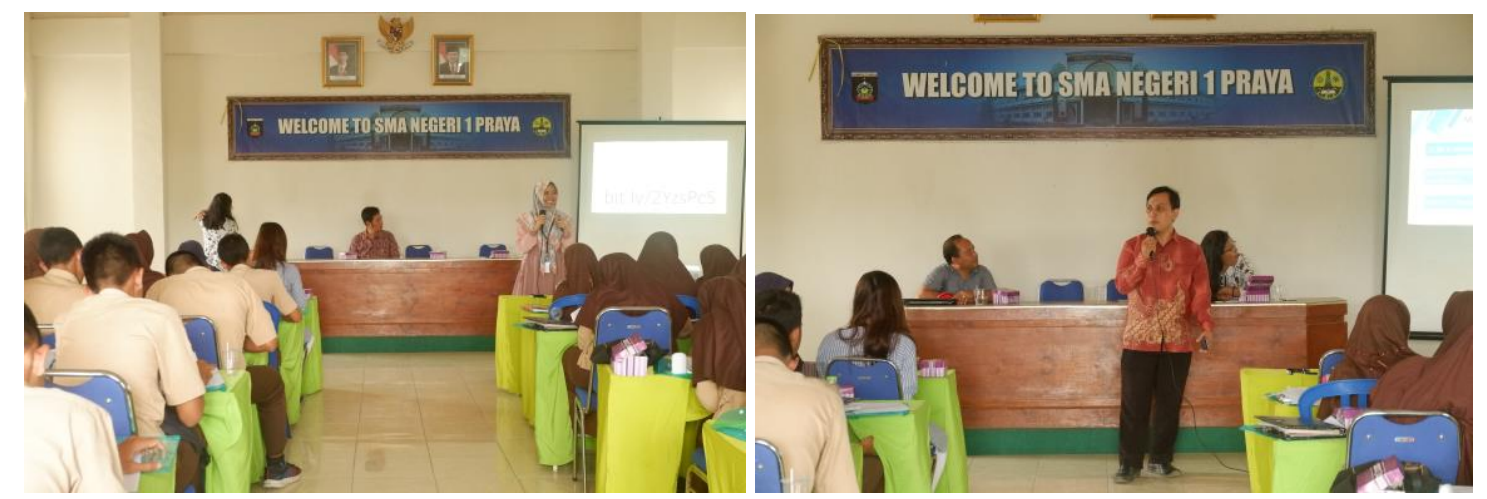

Gambar 1. Pemaparan Materi Peranan Statistika dan Pengembangan Karakter

Setelah pemaparan materi peranan statistika dalam Revolusi Industri 4.0 dan Big Data, kegiatan dilanjutkan dengan pemberian materi yang berkaitan dengan pengembangan karakter dalam menghadapi tantangan era revolusi industri 4.0 dan big data. Materi ini bertujuan untuk meningkatkan pengetahuan siswa agar mereka bisa tahu tentang softskill dan hardskill yang perlu dikembangkan saat ini, bagaimana mengukurnya, dan bagaimana hal ini sangat berpengaruh pada masa depan mereka. Materi ini dimulai dari pemaparan definisi, contoh dalam kehidupan nyata, bagaimana cara menilai, dan hardskills dan softskills yang harus mereka siapkan dalam menghadapi era big data dan revolusi Industri 4.0 ini.

Tabel 1. Hasil Pre-Test dan Post-Test Pengabdian

\begin{tabular}{llrrrr}
\hline \multirow{2}{*}{ No } & \multicolumn{1}{c}{ Kemampuan } & \multicolumn{2}{c}{ Pre-test } & \multicolumn{2}{c}{ Post-Test } \\
& & Ya & Tidak & Ya & Tidak \\
\hline A. & Pengetahuan Statistika & & & & \\
1. & Pengetahuan Statistika & $72 \%$ & $28 \%$ & $91 \%$ & $9 \%$ \\
2. & Penerapan Statistika dalam kehidupan & $52 \%$ & $48 \%$ & $91 \%$ & $9 \%$ \\
3. & Pentingnya Statistika dalam kehidupan sehari-hari & $78 \%$ & $22 \%$ & $93 \%$ & $7 \%$ \\
4. & Pengetahuan tentang Revolusi Industri 4.0 dan Big Data & $16 \%$ & $84 \%$ & $79 \%$ & $21 \%$ \\
5. & Peranan Revolusi Industri 4.0 dan Big Data dalam kehidupan sehari-hari & $7 \%$ & $93 \%$ & $72 \%$ & $28 \%$ \\
B. & Pengetahuan Softskills dan hardkills & & & \\
1. & Pengetahuan softskills & $45 \%$ & $55 \%$ & $98 \%$ & $2 \%$ \\
2. & Pengetahuan hardskills & $45 \%$ & $55 \%$ & $97 \%$ & $3 \%$ \\
3. Softskills dan hardskills yang perlu dimiliki untuk menghadapi era Big & $21 \%$ & $79 \%$ & $67 \%$ & $33 \%$ \\
\hline
\end{tabular}

Setelah pemaparan materi, para siswa melakukan post-test dengan pertanyaan yang sama ditambah dengan pertanyaan terbuka untuk mengevaluasi rangkaian kegiatan pengabadian dalam sudut pandang siswa, dan juga sebagai bahan evaluasi pengabdian kedepan. Setelah itu hasil dari posttest berupa pertanyaan tertutup ditampilkan dan dijelaskan sehingga tim pengabdian dan para siswa 
bisa bersama-sama melihat hasilnya sekaligus sebagai bahan evaluasi kegiatan tersebut, sedangkan hasil dari pertanyaan terbuka di analisis tim dosen untuk pengembangan pengabdian lebih lanjut.

Dari hasil pre-test terlihat bahwa pengetahuan siswa tentang Revolusi Industri 4.0 dan Big Data masih rendah sekitar $16 \%$ sedangkan pengetahuan tentang peranannya sebesar $7 \%$, sehingga dari sini kita bisa melihat bahwa bisa jadi mereka tidak tahu dengan istilah tersebut padahal sudah menjadi keseharian mereka, sehingga merekapun tidak tahu peranannya.

Setelah diberikan pemaparan tentang apa itu Revolusi Industri 4.0 dan Big Data yang disertai dengan ilustrasi dan video, dan contoh-contoh yang relevan dengan kehidupan-sehari peserta didik, mereka menjadi memahami lebih dalam tentang materi tersebut sehingga pemahaman mereka tentang pengetahuan dan peranan Revolusi Industri 4.0 dan Big Data menjadi lebih meningkat sebesar 84\% untuk pemahamannya dan $93 \%$ untuk peranannya.

Dalam pengembangan karakter, rata-rata mereka kurang mengetahui karakter yang harus dikembangkan dalam menghadapi era tersebut, terlihat dalam pre-test bahwa pemahaman mereka tentang keterampilan (hardskills) dan karakter (softskills) yang harus dimiliki masih $45 \%$ sedangkan pemahaman tentang pengembangan karakter yang harus dibangun dalam menghadapi era tersebut masih $21 \%$, dan setelah diberikan pemahaman melalui pembelajaran langsung disertai dengan ilustrasi dan video yang berkaitan, hasilnya pemahaman siswa meningkat hampir sebesar 98\%, sedangkan untuk pengembangan karakternya meningkat menjadi $67 \%$, peningkatan pengetahuan ini belum bisa maksimal mengingat penjelasan tentang materi untuk pengembangan karakter ini kurang begitu mendalam, karena masih dijelaskan sebatas teori belum direncanakan dengan simulasi yang kemungkinan bisa meningkatkan pemahaman lebih baik lagi.

Metode yang digunakan dalam pengabdian ini dirasakan cukup efektif dalam membantu meningkatkan pemahaman para peserta didik dalam memahami materi, karena pemateri bisa menyiapkan materinya berdasarkan pengalaman dan penelitian-penelitian terbaru yang berkaitan, dan memberikan pengajaran langsung kepada siswa. Tetapi masih terlihat ada beberapa kekurangan, diantaranya adalah kurangnya partisipasi aktif dalam pembelajaran, sehingga metode perlu dikombinasikan dengan metode partisipasi siswa (cooperative learning) sehingga para siswa juga bisa aktif secara langsung dalam pendalaman materi, kemudian dalam pengembangan karakter sebaiknya ditambah dengan metode experience learning atau pembelajaran melalui pengalaman, berupa simulasi pengembangan karakter sehingga siswa bisa merasakan langsung bagaimana mereka bisa mengembangkan karakter mereka dalam kehidupan sehari-hari sehingga mereka lebih siap dalam menghadapi era ini.

Selanjutnya, dari hasil pertanyaan terbuka terlihat bahwa para siswa merasakan manfaat dari pengabdian ini diantaranya adalah mereka bisa mengenal lebih dalam tentang peranan statistika dalam kehidupan sehari-hari dan dalam menghadapi era big data dan revolusi industri 4.0 ini, serta mereka bisa lebih siap menghadapi tantangan tersebut dengan meningkatkan kompetensi mereka khususnya hardskills dan softskills.

\section{KESIMPULAN DAN SARAN}

Pengabdian ini memperlihatkan bahwa adanya peningkatkan pengetahuan para peserta didik terhadap Peranan Statistika dan Pengembangan Karakter dalam Menghadapi Era Revolusi Industri 4.0 dan Big Data di SMAN 1 Praya. Kegiatan sosialisasi tentang pentingnya peranan statistika dan pengembangan karakter dalam menghadapi tantangan era revolusi industri 4.0 dan big data sangat 
perlu dilaksanakan di Sekolah-sekolah Menengah khususnya di Nusa Tenggara Barat, sehingga para siswa bisa sadar dan tanggap dalam menghadapi tantangan ini, dan mempersiapkan diri sebaikbaiknya. Oleh sebab itu, maka sangat disarankan apabila pengabdian selanjutnya bisa dilakukan di sekolah-sekolah menengah yang lain baik Sekolah Menengah Atas (SMA), Sekolah Menengah Kejuruan (SMK) atau Madrasah Aliyah (MA) baik negeri maupun swasta. Kemudian dengan lebih mengemas materi statistika agar lebih menarik dan bisa dipraktekan secara langsung dengan alat yang tersedia seperti smartphone atau komputer, sehingga kemampuan peserta bisa meningkat dan terukur dengan baik dan juga pengemasan materi pengembangan karakter yang didesain agar praktis dilakukan, berkesinambungan dan terukur, karena pembelajaran karakter ini tidak akan berhasil bila tanpa adanya pembiasaan dan evaluasi yang terus menerus.

\section{Ucapan Terima Kasih}

Penulis mengucapkan terima kasih kepada LPPM Universitas Mataram yang telah memberi dukungan financial terhadap pengabdian ini.

\section{DAFTAR PUSTAKA}

Majelis Pendidikan Dewan Pendidikan Tinggi Kementerian Riset, Teknologi dan Pendidikan Tinggi. 2017. Memandang Revolusi Industri dan Dialog Pendidikan Karakter di Perguruan Tinggi Indonesia. Kemenristekdikti: Jakarta.

Maryanto, Budi. 2017. "Big Data dan Pemanfaatannya dalam Berbagai Sektor" Media Informatika 16 (2): 14-19.

Prasetyo, Banu, and Umi Trisyanti. 2018. "Revolusi Industri 4.0 dan Tantangan Perubahan Sosial." Prosiding SEMATEKSOS 3 "Strategi Pembangunan Nasional Menghadapi Revolusi Industri 4.0" 22-27.

Yahya, Muhammad. 2018. Era Industri 4.0: Tantangan dan Peluang Perkembangan Pendidikan Kejuruan Indonesia. Universitas Negeri Makassar: Makasar. 